\title{
Lee Goodglick-In Fond Memory
}

\author{
Michael C. Fishbein \\ Department of Pathology and Medicine David Geffen School of Medicine at UCLA; 10833 Le Conte Ave Los Angeles, \\ CA; Phone: 310 825-9731; Fax: 310 794-4161; mfishbein@mednet.ucla.edu
}

When I arrived at UCLA in July of 1997, Dr. Lee Goodglick was Director of the Human Tissue Research Center, in the Department of Pathology \& Laboratory Medicine, at UCLA. Lee was a scientist at UCLA for 25 years specializing in research in cancer, before that disease took his life. Although our laboratories were on the same corridor in the 1P area, we interacted very little at first, until we were asked to collaborate to write the pathology core portion of a SPORE grant (Specialized Center of Research Excellent) in lung cancer, and later other grant applications. I can say that all of these were successful applications mainly due to Lee's skills, knowledge, and experience as an investigator and scientist and his exceptional writing skills. His scientific excellence carried me along in these research efforts.

At some point, Lee and I had to look at slides under the microscope to quantitate histologic findings. Looking at hundreds of slides was an important but tedious and time-consuming task. We decided to review the slides together, to give a "consensus" grad- ing, rather than individual evaluations. Had we not done this, the process would have been boring, and I would not have had the opportunity to know Lee at all. Lee made the process for me fun, interesting, and educational. I actually looked forward to the hours we spent together at the microscope. I learned about so many things: religion, politics, world affairs, and sports teams, mainly the Lakers.

I also learned a lot about Lee-his own religious and political beliefs, his love of family,and of course, his love of basketball. He told me about the Friday nights with the family, asking his nieces and nephews philosophical questions at the dinner table. And of course, later on, when he married Rietta and adopted Joseph, it was obvious that they were the loves of his life. Lee was truly a spiritual person. He had a quiet strength, and unmatched moral and ethical standards. He was kind and generous in thought and action. Lee did not speak harshly, or badly about anyone. He certainly made me a better scientist, a better-informed citizen, and also a better person. I miss those sessions at the microscope. 